\title{
Improving photovoltaics grid integration through short time forecasting and self-consumption
}

\author{
D. Masa-Bote ，M. Castillo-Cagigal , E. Matallanas , E. Caamaño-Martín , A. Gutiérrez , \\ F. Monasterio-Huelín , J. Jiménez-Leube
}

H I G H L I G H T S

- Uncertainty in PV generation forecast is a drawback for grid integration.

- Self-consumption of distributed PV reduces the effect of forecast uncertainty.

- Active Demand Side Management and local storage increases self-consumption.

- Experimental results and simulations are presented.

- Error on electricity exchanged with the grid is reduced to $2 \%$.

\begin{abstract}
A B S T R A C T
The uncertainty associated to the forecast of photovoltaic generation is a major drawback for the widespread introduction of this technology into electricity grids. This uncertainty is a challenge in the design and operation of electrical systems that include photovoltaic generation. Demand-Side Management (DSM) techniques are widely used to modify energy consumption. If local photovoltaic generation is available, DSM techniques can use generation forecast to schedule the local consumption. On the other hand, local storage systems can be used to separate electricity availability from instantaneous generation; therefore, the effects of forecast error in the electrical system are reduced. The effects of uncertainty associated to the forecast of photovoltaic generation in a residential electrical system equipped with DSM techniques and a local storage system are analyzed in this paper. The study has been performed in a solar house that is able to displace a residential user's load pattern, manage local storage and estimate forecasts of electricity generation. A series of real experiments and simulations have carried out on the house. The results of this experiments show that the use of Demand Side Management (DSM) and local storage reduces to $2 \%$ the uncertainty on the energy exchanged with the grid. In the case that the photovoltaic system would operate as a pure electricity generator feeding all generated electricity into grid, the uncertainty would raise to around $40 \%$.
\end{abstract}

\section{Introduction}

Over the last years the amount of photovoltaic power installed worldwide has been increasing steadily [1]. This growth responds to various reasons, among which stand out the increasing awareness of global warmth caused by greenhouse emissions, the inevitable exhaustion of traditional energy sources in the following decades (fossil fuels) and the need for countries to assure energy self-dependence [2,3]. Photovoltaics (PV), as well as other renewable energies, provide safe and clean electricity and, moreover, can play an important role in the solution of the aforementioned problems. The growth ratio of the PV installed capacity increases every year, so that the cumulative capacity shows an exponential behaviour [1]. It is noteworthy that this trend has been maintained also in recent years when some countries, particularly in Europe, started to cut down on subsidies and feed-in-tariffs. As a consequence of this growth the effect of photovoltaic power connected to public utilities begins to be noticeable for the overall system. For example, in Spain and Germany the share of electricity 
produced by grid-connected PV during 2010 was $2.3 \%$ and $1.9 \%$ respectively $[4,5]$. The share of electricity produced by PV and other renewable energies is expected to grow in the following years [6-9].

As the share of electricity produced by PV increases, the need for photovoltaics to be fully integrated into electricity grids arises. Fully integration of a generator into the grid requires that the electricity produced by the generator is known beforehand. With this knowledge, the generator can be included in grid planning and it would be possible to dynamically adjust its output in response of real time demands from the grid. Traditionally, photovoltaic energy, together with other renewable energies like wind, has been considered to be a non-controllable, unpredictable electricity source. In consequence, it has not been regarded as a reliable energy source by grid operators. The unreliability of PV is due to its dependence on meteorological conditions: irradiance and temperature. If these two meteorological variables could be forecasted with sufficient precision, it would be possible to estimate the electricity production of a PV system. In addition, photovoltaics will become a more reliable electricity source.

The use of forecast techniques to enable grid integration of PV electricity $[10,11]$ (and also other renewable energies such as wind $[12,13])$ has been previously addressed in the literature. Despite efforts to improve forecast techniques, they still incur in high error rates. For this reason, some authors have suggested alternative schemes that would make possible the goal of grid integration. Some of these schemes are the use of local storage in combination with renewable energy generators in order to rectify deviations between forecasted and produced electricity [14] or the combination of a large amount of PV generators distant from each other so individual errors are independent and the overall forecast error is reduced [6].

At the same time that renewable energies are being deployed and are expected to play a major role in the generation of electricity, the traditional conception of distribution grids as passive drains of electricity is shifting towards a more active one with the inclusion of Demand-Side Management (DSM) and storage which allow demand to adapt dynamically to generation [15-19]. This new paradigm of distribution grids is based upon the smart grid concept $[20,21]$. This paper proposes a novel mechanism for integrating small sized PV generators in the residential sector that brings together the aforementioned elements: PV forecasts, DSM and local storage. Active Demand-Side Management (ADSM) is a new concept derived from the addition of automatic load control to DSM strategies [22]. In this situation, the concept of self-consumption arises, i.e. the local consumption by loads of the electricity generated by the PV system. Self-consumption also provides an alternative for photovoltaics exploitation on the current scenario of increasing electricity retail prices and decreasing feed-in-tariffs. Users can reduce the electricity bill by the use of their own generated electricity. In some countries, like Italy, in addition to the financial incentive gained by selling electricity to the retailers there is also an incentive for the self-consumption of PV generated electricity [23]. From a technical perspective, some authors have pointed that distributed PV generation can provide directly as much as $20-25 \%$ of a city demand if no additional measures are taken and $50-75 \%$ of electricity demand if Demand-Side Management and storage are used [24-26].

Although this approach to PV integration in the grids has several advantages (e.g.: mitigation of forecast error through battery usage, displacement of peak demand and flattening of demand profile, reduction of system losses associated to transport and distribution, provision of ancillary services like voltage control via reactive electricity feeding), there is no previous results on this subject apart from theoretical studies. This paper explores, as proof of concept, this possibility for PV integration in the residential sector to demonstrate that it is feasible and that the uncertainty in PV generation can be made negligible.

The remainder of this paper is as follows. Section 2 presents Magic Box, a solar house, which combines the aforementioned elements: PV generation, local electricity storage and a control system which is responsible of performing the ADSM, managing the storage and forecasting electricity generation. Section 3 introduces the methodology employed in this study to evaluate the achieved level of self-consumption. Section 4 presents the results of a measurement campaign carried out on Magic Box. On Section 5 a comparison of two of the most popular forecasting techniques, numeric weather prediction models and time series analysis, is presented. Conclusions are summarized on Section 6. Finally, two annexes which describe the forecast models employed are appended to the paper.

\section{Magic Box and GEDELOS-PV system}

Fig. 1 shows a block diagram of the system composed by the combination of Magic Box and the GEDELOS-PV system. Black solid lines indicate the power/energy flows between the different elements capable of delivering electricity -PV generator, storage and the grid- or consume it -loads, storage and the grid-. The blue dotted arrows show the information received by the ADSM system from the different system elements. Finally, the red dashed arrow shows the flow direction of the actuation commands from the ADSM system to the loads. The user interacts with the system through the loads set-up via the ADSM system. Magic Box and the GEDELOS-PV system are explained in detail below.

\subsection{Magic Box}

Magic Box is an energy self-sufficient solar house located in the grounds of the Technical University of Madrid, Spain (UPM). Magic Box was the first house from a European university to take part in the international competition Solar Decathlon [27,28], it is used now as a research laboratory at the UPM. This solar house has been used to assess the effect of the combination of PV generation forecasts, load management and local storage on the electric grids. The house is based on AC topology, where electricity is exchanged between the different elements -PV generators, storage, loads and grid- through an AC bus. This topology does not impose an explicit hierarchy to the energy elements and, therefore, it increases system scalability.

\subsubsection{Photovoltaic system}

The PV system produces energy that can be: either used locally by the loads, stored in the batteries or fed into the grid. It is divided into five independent generators of monocrystalline silicon technology distributed in four different south-oriented surfaces whose tilt angles are: $12.5^{\circ}, 25^{\circ}, 40^{\circ}$ and $90^{\circ}$. Each PV generator is connected to a single string-type inverter. The combined peak power of the five generators is $6.2 \mathrm{~kW}$.

The photovoltaic system also incorporates a meteorological station and monitoring equipment. The meteorological station has the following sensors: four reference PV sensors for the measurement of irradiance [29] (one cell for each tilt angle) and a PT-100 resistor for the measurement of ambient temperature. The monitoring equipment records every five minutes values from the sensors in the meteorological station as well as $A C$ and DC power, current and voltage from the five PV generators. Additionally, a precision energy meter (class 1 [30]) records the AC energy produced by the whole PV system every minute. 


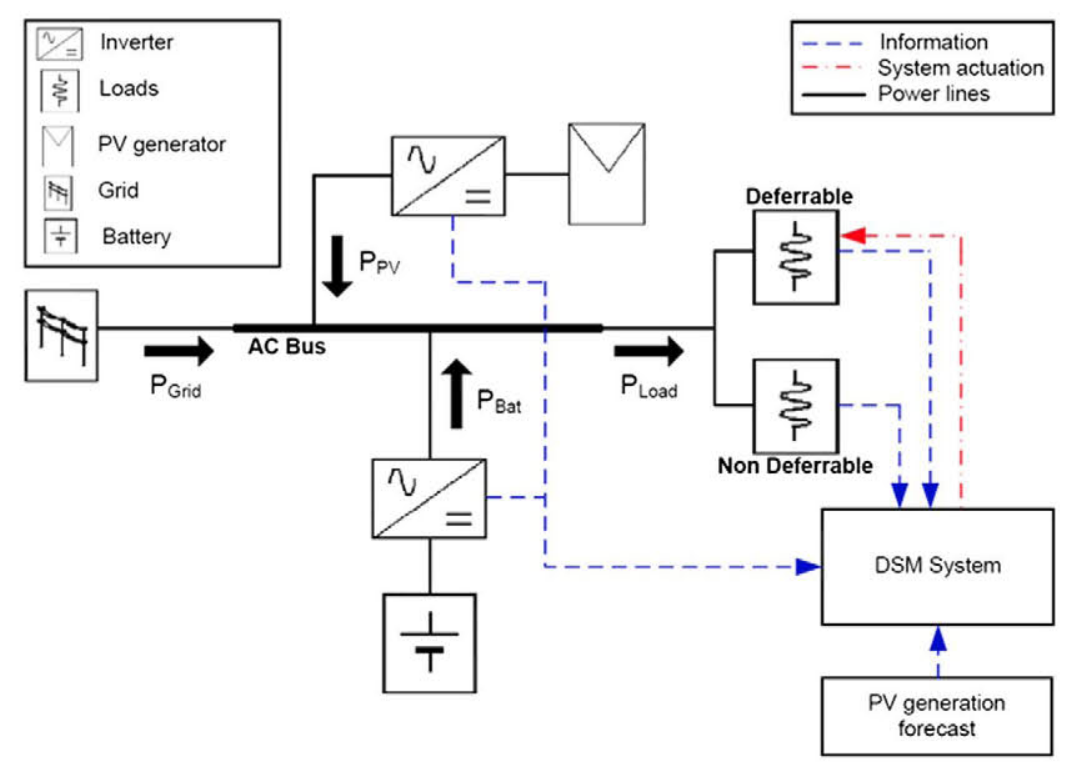

Fig. 1. Local grid configuration.

\subsubsection{Storage system}

The local storage system consists of a bank of lead-acid batteries and a bidirectional inverter. The battery bank is formed by 24 cells, the voltage of each cell is $2 \mathrm{~V}$ and the capacity for a ten hour discharge cycle is $750 \mathrm{Ah}$. Therefore, the nominal storage capacity of the bank is $36 \mathrm{kWh}$. The battery inverter has a nominal AC power of $5 \mathrm{~kW}$.

\subsubsection{Loads}

The loads present in the house are typical of a highly electrified house: electric oven, cooker, hood, refrigerator, dishwasher, washing machine, dryer, lights, computers and entertainment applications. The loads have been classified into two categories: deferrable loads and non-deferrable ones. Deferrable loads can be displaced along the day because they do not require an instantaneous execution, e.g.: washing machine, dryer, dishwasher. The deferrable loads are connected to a home automation system that allows remote control of deferrable loads and monitors the state of the loads. A load is considered non-deferrable when its energy demand cannot be moved in time: it must run at the time asked by the user (e.g.: TV and lighting) or it must run continuously (e.g.: fridge).

The consumption of all loads, deferrable and non deferrable, is measured by a power meter. The scheduling of deferrable loads is performed by the ADSM system as explained below.

\subsection{GEDELOS-PV system}

The GEDELOS-PV system is able to displace the consumer's load profile and controls the local storage system; thereby it modifies the energy balances between the system elements according to user's preferences and the criterion of maximizing self-consumption. Therefore, users can take an active part in the electric system. The system assures that all loads will always receive the electricity they need. This electricity will be fed, when necessary, by a combination of photovoltaics, battery and grid. The priority of the three sources, from most important to least, is as follows: photovoltaics (primary source), battery (secondary source) and grid (tertiary source). The GEDELOS-PV system is conceived as a distributed system, so its function does not rely on any centralized agent [31].

\subsubsection{ADSM system}

The ADSM system is responsible for scheduling the deferrable loads along the day. The user sets in the control system the execution time in which deferrable loads have to run, e.g.: execute the washing machine between $10: 00$ and 16:00. This means that the load has to be executed within this time interval, independently of energy availability. The ADSM system receives PV generation forecasts and schedules the deferrable loads in order to optimize energy criteria using the time interval constriction. The ADSM optimization criterion shown in this paper is to maximize the self-consumed energy. Specific technical details of the ADSM system operation are explained in [32,33].

\subsubsection{Battery controller}

A high level software battery controller has been developed. This controller performs the following tasks: (i) it preserves battery lifetime by avoiding excessive charge or discharge; (ii) it assures that there are no energy exchanges between the battery and the grid; the battery is only charged with the excess of PV electricity and discharges to the loads, maximizing self-consumption; (iii) it allows to adjust the usable capacity of the battery to levels that are suitable to the usual consumption of an individual household. The battery controller operation is explained in detail in [34].

Although electricity exchange between grid and electrical storage is beneficial for the grid, either if the storage is distributed [16] or centralized [18], the possibility to charge the battery from the grid or discharge it to the grid has not been considered for the GEDELOS-PV system. This decision is motivated in the fact that electricity exchange on the demand-side between grid and storage is forbidden in many European countries, including Spain.

\subsubsection{Estimation of electricity forecasts}

The GEDELOS-PV system receives hourly forecasts of irradiation and ambient temperature for the next day, which are provided externally to the system. These meteorological forecasts are estimated for Madrid $\left(40.5^{\circ} \mathrm{N}, 3.7^{\circ} \mathrm{W}\right)$, where Magic Box is located. From these meteorological forecasts the GEDELOS-PV system estimates the usable electricity, $E_{A C, P V}$, of the PV system in Magic Box for the next day, according to the model of Eq. (1).

$E_{A C, P V}=E_{D C, M A X} \cdot\left(1-L_{S H}\right) \cdot\left(1-L_{C O}\right) \cdot\left(1-L_{S}\right)$ 
where $E_{D C, M A X}$ is the maximum DC electricity that the PV generator can deliver, $L_{S H}$ are the losses due to shading, $L_{C O}$ are optical losses and $L_{S}$ are system losses. $E_{D C, M A X}$ depends mainly on operation conditions: irradiation and cell temperature.

Maximum DC electricity depends on operating conditions, namely irradiation and cell temperature and thus incorporates thermal losses $L_{T H}$ (not explicitly included in Eq. (1)), which are due to the cells operating at a temperature different from $25^{\circ} \mathrm{C}$ : $E_{D C, M A X}$ has been estimated with the model proposed by Osterwald [35]. Since Osterwald model requires cell temperature but only ambient temperature is available, the Nominal Operation Cell Temperature model has been used to convert from ambient temperature to cell temperature [36]. Shading losses are caused by shadows casted by nearby obstacles over the PV generator. They have been estimated using a model developed by the authors [37]. Optical losses are caused by soiling over the surface of the PV generator and by the reflection of incident light when incidence angle is different than perpendicular. The model proposed by Martín has been used to estimate optical losses [38]. System losses account for the instantaneous DC-AC conversion efficiency of the inverter. The model proposed by Schmidt [39] has been selected to estimate system losses. Electrical losses, such as voltage drops or modules mismatch, have not been considered separately in Eq. (1) because their effect is included in the model for maximum DC electricity via the on-site characterization of the PV generators. The Maximum Power Point Tracking (MPPT) efficiency of the inverters has been disregarded (MPPT efficiency of $100 \%$ ).

\section{Methodology for system analysis}

In the most generic system, apart from the loads and the PV generator, the grid and the storage system, usually a battery, would also be present. This leads to the energy balance equation shown in Eq. (2):

$E_{P V}+E_{\text {Bat }}+E_{\text {Grid }}=E_{\text {Load }}$

where $E_{P V}$ is the PV generated energy; $E_{B a t}$ is the electricity exchanged with the storage system, defined as positive when the storage system feeds the loads; $E_{\text {Grid }}$ is the electricity exchanged with the grid, defined as positive when the grid feeds the loads; $E_{\text {Load }}$ is the consumed electricity by the loads.

Within this scenario, a figure of merit, first defined by the authors in [34], has been used in this paper to evaluate the selfconsumption level achieved by a system that combines local load consumption and PV generation: the self-consumption factor, $\xi_{L}$. This factor is defined in Eq. (3).

$\xi_{L}=\frac{E_{P V \rightarrow L}+E_{\text {Bat }, P V \rightarrow L}}{E_{\text {Load }}} \in[0,1]$

where $E_{P V \rightarrow L}$ is the electricity directly supplied to the loads by the PV system and $E_{B a t, P V \rightarrow L}$ is the photovoltaic electricity supplied to the loads by the storage system. Notice that in a system without storage this second term should be omitted.

Parameter $\xi_{L}$ measures the fraction of local demand that is satisfied by local generation: $\xi_{L}=0$ corresponds to the case in which there is no local generation and $\xi_{L}=1$ corresponds to the case of local generation fully supplying the loads. This figure of merit is normalized so it allows direct comparison of systems with different loads or generators.

\section{Measurement campaign}

A measurement campaign on the prototype Magic Box was carried out in order to assess the behaviour of GEDELOS-PV system with regard to PV electricity forecasts and self-consumption. A total of 56 experiments were performed during this campaign, each experiment consists of one day of operation of the house. These experiments were not performed on consecutive days; instead, they were distributed over a period of one year. Groups of experiments were performed in each season, in order to cover different weather conditions. 29 of these experiments were carried out without ADSM to differentiate between natural self-consumption, achieved by the concurrence of distributed generation and local consumption, and self-consumption achieved by the GEDELOSPV system. The remaining experiments (27 days) were carried out with ADSM enabled. The non-deferrable loads present in the house operated at fix times to simulate the typical behaviour of an average user. The deferrable loads were either operated at the times scheduled by the GEDELOS-PV system or at fix times for experiments without ADSM. The electricity demanded by the loads varied between experiments, with the daily electricity consumed in the range of $5-10 \mathrm{kWh}$, typical average of residential consumers in Spain [40]. Approximately $20 \%$ of this electricity corresponds to deferrable loads. The usable capacity of the battery was set to $6 \mathrm{kWh}$ for all days. Previous works have shown that this autonomy level is reasonable to optimize self-consumption in residential environments [32,33]. For all days in the measurement campaign hourly values of electricity generation were forecasted the previous day using as inputs meteorological forecasts generated by the HIRLAM model, a numerical weather prediction model (NWP). Additional information on the HIRLAM model is provided in Appendix A.

\subsection{Results}

Table 1 shows a summary of the results of the measurement campaign. Experiments have been grouped by season; for each season, the average self-consumption factor and the error in forecast of daily electricity generation are given. The self-consumption factor $\xi_{L}$ is higher in days with ADSM than in days without ADSM. Despite the small fraction of electricity demand considered deferrable in these experiments, the use of ADSM increases the self-consumption factor. The self-consumption factor is higher for summer and spring, when more solar irradiation is available, than in winter and autumn. It must be noted that the GEDELOS-PV system does not know when the deferrable loads operate and how much electricity is demanded by them. In consequence, the system cannot take any measure to overcome this random behaviour and the consumption of non-deferrable loads limits the maximum self-consumption factor that can be achieved. However, the use of the local storage, which stores electricity during the day and provides it to the loads after the sunset, alleviates the effect of this randomness because most of the non-deferrable loads were set to operate in the evening to imitate the behaviour of average residential users.

The daily $\xi_{L}$ for all experiments is presented in Fig. 2; the black solid lines correspond to the average values of self-consumption factor for every season. The dispersion of values around the

Table 1

Results of measurement campaign: mean values of daily self-consumption factor and daily electricity generation forecast error.

\begin{tabular}{lllllc}
\hline \multirow{2}{*}{ Season } & \multicolumn{2}{l}{ Without load management } & & \multicolumn{2}{l}{ With load management } \\
\cline { 2 - 3 } \cline { 5 - 6 } & $\xi_{L}(-)$ & Forecast error $(\%)$ & & $\xi_{L}(\%)$ & Forecast error $(\%)$ \\
\hline Summer & 0.77 & 17.6 & 0.80 & 23.7 \\
Autumn & 0.68 & 13.8 & 0.74 & 131.0 \\
Winter & 0.69 & 27.8 & 0.64 & 49.4 \\
Spring & 0.83 & 23.8 & 0.96 & 33.2 \\
Year & 0.73 & 26.5 & 0.79 & 64.0 \\
\hline
\end{tabular}



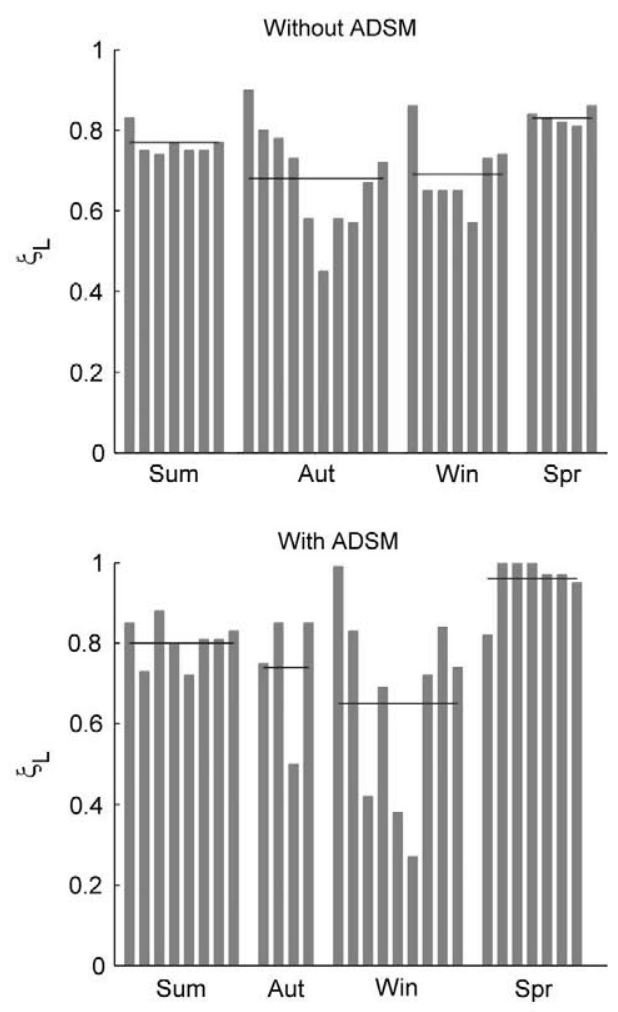

Fig. 2. Daily self-consumption for experiments without ADSM (upper figure) and with ADSM (lower figure).

average is higher in winter and autumn, which is coincident with the fact that the self-consumption factor for these seasons is also lower. During spring and summer, when $\xi_{L}$ is high, the scattering of values is reduced.

Table 1 also shows that forecast errors are significantly higher for autumn and winter than for summer and spring. This fact corresponds to the characteristics of the climate at Madrid; the weather in autumn and winter is very unstable with sunny days succeeding cast days and vice versa. This instability affects negatively the accuracy of electricity forecasts due to the fact that the accuracy in forecasting is highly dependant on the variability (as measured, for example, by the variance) of the forecasted variable. The dependence of forecast accuracy on irradiation variability has been previously reported in literature [41-43]. It must be noted that the low forecast error for the experiments without load management during autumn is a misleading result because the days selected for those experiments happened to be good days in terms of predictability. The results of the days with ADSM show that there is not relationship between forecast error and self-consumption.

\section{Comparison of forecast models}

The results of the measurement campaign showed that a high level of self-consumption is attainable through the combination of electricity generation forecasts and ADSM. Based upon these results the operation of Magic Box was simulated with a twofold purpose: (i) to evaluate over the course of a year whether the use of ADSM can mitigate the uncertainty in PV generation forecast; and (ii) to test and additional forecast model besides the one used during the measurement campaign. During the measurement campaign the HIRLAM model was used because a NWP model is the more straightforward manner to obtain forecast of meteorological variables. However, an external provision of forecasts poses a drawback given the decentralized conception behind the GEDE-
LOS-PV system. Numeric weather prediction models require a vast amount of computational effort and, therefore, it is not feasible to execute such models locally by small sized PV systems such as GEDELOS-PV. Instead, they operate in a centralized manner with only one instance of the model providing forecasts for a wide region. For this reason, a distributed model that allows for the estimation of forecasts locally from on-site measurements was included in this study. There are several models that can be considered as distributed in the literature. Among these models, autoregressive integrated moving average models (ARIMA) and artificial neural networks provide the best results with no significant differences between these two [41-44]. Finally, the ARIMA model was chosen because of its simplicity. ARIMA models are described in Appendix B.

In order to evaluate the effect of forecast uncertainty on the electricity exchanged with the grid both forecast models, ARIMA and HIRLAM, were benchmarked against a virtual reference model. This model, called the ideal predictor, forecasts meteorological variables without error, that is, the forecasts for the next day are the actual, measured values on that day. The ideal predictor would correspond to the case in which the photovoltaics outcome is known and, therefore, the closer the system behaves to the ideal predictor the less effect of forecast uncertainty on the electricity that is exchanged with the grid. It must be noted that the ideal predictor is a virtual forecast model that cannot be considered a real forecast model because it requires for the time period being forecasted to be already elapsed.

Magic Box behaviour was simulated during one year for every forecast model, in order to cover all possible weather conditions. Two storage sizes were considered for every model: 0 days of autonomy - no storage - and 0.5 days of autonomy. The forecasts of PV electricity for the simulations have been estimated from a year of real meteorological data. The same year was used for all experiments in order to compare the models under the same meteorological conditions. Daily load consumption was considered the same throughout the year and equal to $11 \mathrm{kWh}$, of which $2.2 \mathrm{kWh}$ were deferrable. This daily consumption amounts to $4 \mathrm{MWh}$ of annual electricity consumption, which is typical for a Spanish household of 3-4 members and is also coincident with typical consumption of average households in other European countries $[29,45]$. The profile of the non-deferrable loads has been modelled according to the behaviour of an average consumer [29]. However, it must be noted that consumer behaviour in terms of load profile is not affected by socio-economic factors like head of the household's age, region, population or employment status of inhabitants. The average load profile used in this study can be considered as representative of the majority of Spanish households. In all cases, residential demand is characterized by very low consumption during night and morning and most of electricity needs happening around $10 \mathrm{pm}$. In consequence, residential demand is offset with respect to PV generation. The load profile in other European countries resembles the Spanish profile though it is shifted one hour and the peak demand occurs earlier [35]. The demand of non-deferrable loads is never known by the GEDELOS-PV system neither in time of operation nor in demanded electricity. In this way, the non-deferrable demand is totally random for the system. With respect to deferrable loads, it has been considered that the user is involved in increasing self-consumption and follows the recommendations given by the GEDELOS-PV system. It must be stressed once again that the system always gives the highest priority to the user's preferences, provided to the system prior to scheduling the loads for the next day.

The actual electricity generated by the PV system in Magic Box during the year used in the simulations was $7300 \mathrm{kWh}$. The losses specified in Eq. (1) as well as the overall performance of the system (performance ratio PR) are given in Table 2 . The overall 
Table 2

Losses and performance of the PV system.

\begin{tabular}{lc}
\hline Parameter & Value (\%) \\
\hline$L_{T H}$ & 7.5 \\
$L_{S H}$ & 15.8 \\
$L_{C O}$ & 6.7 \\
$L_{S}$ & 10.65 \\
$\mathrm{PR}$ & 65.0 \\
\hline
\end{tabular}

PR of the system is $65 \%$. The major source of losses is shading, which is usual for building integrated PV systems. The shadows over the PV system, casted by surrounding trees, can be seen in Fig. 3. The performance ratio of the system without considering shadows would be $77.2 \%$.

\subsection{Results}

Fig. 4 shows the distribution of relative errors in the forecasts of daily electricity generation using ARIMA and HIRLAM models. Although one complete year has been simulated, forecasts were only generated for 295 days. 65 days were excluded from the analysis because they were used to build the ARIMA model. For the 300 remaining days an additional set of 5 days was excluded because of corrupt or missing data about actual electricity. Both distributions are centred at $12.5 \%$, meaning that both models tend to overestimate electricity generation. The ARIMA model errors are distributed more symmetrically than the HIRLAM model errors, showing that the tendency to overestimate generation is more acute for the HIRLAM model. This is corroborated by the error accumulated over long periods of time; the error on the energy accumulated over the simulated period was $6 \%$ for ARIMA while for HIRLAM the error was $22 \%$. The bins at the edges of both figures collect all errors higher than $100 \%$, or lower than $-100 \%$. The errors for several days were bigger than $100 \%$ in absolute value, as shown by bins at the edges, for both models. These high errors are caused by sudden drops in daily irradiation when a fully cast day follows a sunny day.

Table 3 summarizes the performance of the two forecast models: the mean absolute percentage error (MAPE) of daily values is shown. The standard deviation of these errors ( $\sigma \mathrm{MAPE}$ ) is also provided in order to illustrate the dispersion of errors around the average value. HIRLAM performs better than ARIMA for daily values in terms of MAPE and standard deviation of errors. The same trends observed in Table 1 are also seen in Table 3. The MAPE and the standard deviation of errors are lower for summer time than for

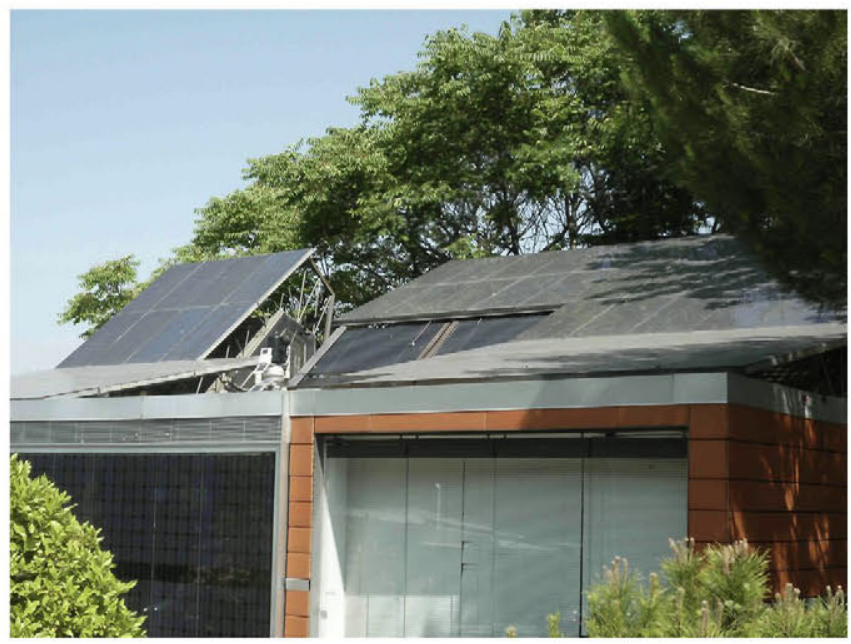

Fig. 3. Picture of Magic Box showing shadows casted by surrounding trees.
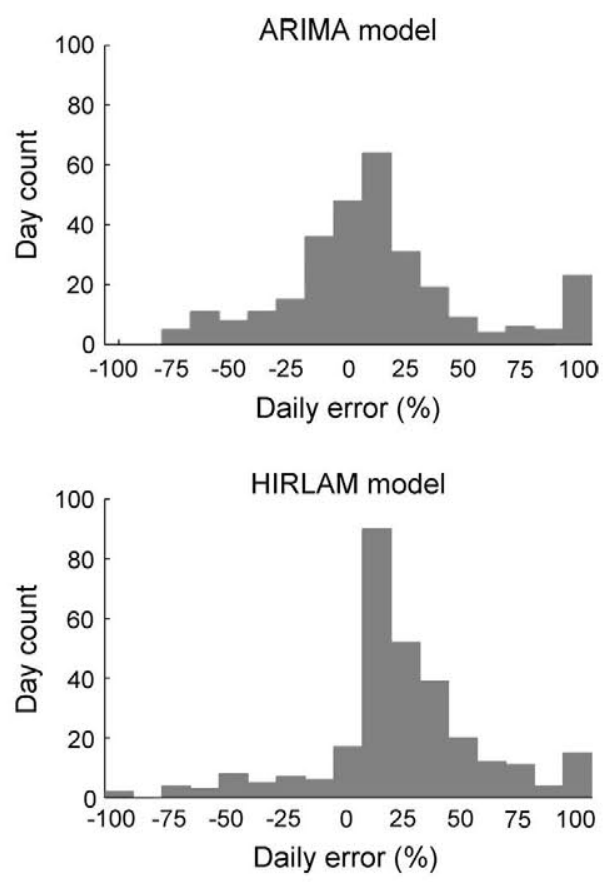

Fig. 4. Histograms of daily forecast errors for ARIMA and HIRLAM models.

Table 3

Performance of forecast models: daily values of mean absolute percentage error (MAPE) and standard deviation of errors ( $\sigma \mathrm{MAPE}$ ).

\begin{tabular}{lllc}
\hline Model & Season & MAPE (\%) & бMAPE (\%) \\
\hline \multirow{2}{*}{ ARIMA } & Summer & 21.2 & 27.8 \\
& Autumn & 70.0 & 124.3 \\
& Winter & 66.9 & 110.6 \\
& Spring & 30.9 & 31.2 \\
HIRLAM & Year & 42.3 & 87.8 \\
& Summer & 26.5 & 27.2 \\
& Autumn & 43.8 & 59.6 \\
& Winter & 39.3 & 35.7 \\
& Spring & 41.5 & 33.6 \\
& Year & 37.2 & 49.4 \\
\hline
\end{tabular}

the rest of seasons. The forecast errors for ARIMA increase highly during winter and autumn compared to the errors during summer and spring. For HIRLAM, although summer is still the best season, there is no significant difference in MAPE for the rest of seasons. Autumn is the worst season in terms of $\sigma$ MAPE while winter and spring shown close results. When looking at the results for the whole year, HIRLAM outperforms ARIMA in both MAPE and GMAPE, with ARIMA being more volatile than HIRLAM and almost doubling the standard deviation of error of the NWP model.

When looking at the self-consumption levels achieved with the 2 forecast methods, the previous differences disappear. In effect, Table 4 shows the average values and standard deviations of the differences between the daily self-consumption factor when ARIMA or HIRLAM models are used and the values achieved when the ideal predictor is used. Compared with the relatively high errors committed in electricity forecast (Table 3) the use of ADSM reduces significantly self-consumption differences between the use of forecast models and the reference (ideal predictor). The use of small-scale storage reduces even further these differences to $2.2 \%$ for ARIMA model and $2.1 \%$ for HIRLAM model. The oMAPE is also reduced to values below $5 \%$ for both models, meaning the occurrence of days with high deviations from the ideal predictor case is very improbable. Regarding seasonal variations, summer is still the best season, with the lowest difference for both models, and 
Table 4

Mean difference of daily self-consumption between forecast models and real predictor for different storage sizes.

\begin{tabular}{|c|c|c|c|c|c|}
\hline \multirow[t]{2}{*}{ Model } & \multirow[t]{2}{*}{ Season } & \multicolumn{2}{|c|}{0 days of autonomy } & \multicolumn{2}{|c|}{0.5 days of autonomy } \\
\hline & & MAPE (\%) & бMAPE (\%) & MAPE (\%) & $\sigma \mathrm{MAPE}(\%)$ \\
\hline \multirow[t]{5}{*}{ ARIMA } & Summer & 4.6 & 6.6 & 1.5 & 3.9 \\
\hline & Autumn & 7.7 & 9.0 & 2.2 & 4.5 \\
\hline & Winter & 8.8 & 11.0 & 3.7 & 7.1 \\
\hline & Spring & 4.6 & 8.3 & 2.6 & 5.0 \\
\hline & Year & 7.0 & 8.6 & 2.2 & 4.9 \\
\hline \multirow[t]{5}{*}{ HIRLAM } & Summer & 3.3 & 5.8 & 1.2 & 3.4 \\
\hline & Autumn & 8.5 & 10.7 & 2.7 & 4.9 \\
\hline & Winter & 6.3 & 7.2 & 1.8 & 3.8 \\
\hline & Spring & 8.0 & 8.2 & 2.6 & 5.0 \\
\hline & Year & 6.5 & 8.8 & 2.1 & 4.6 \\
\hline
\end{tabular}

either winter or autumn are the worst seasons depending on model and storage size. However, the differences between seasons are not as acute as the differences in electricity generation forecast errors.

Fig. 5 shows the self-consumption daily errors obtained with the 2 forecast methods, with and without storage. As shown in the figure, the use of small-scale storage reduces the difference in self-consumption to zero for many days, $49 \%$ of total number of days for ARIMA and 54\% for HIRLAM. In these days, Magic Box, with the GEDELOS-PV system operating, behaves exactly the same that when electricity generation by the PV system is accurately known beforehand - ideal predictor. This implies that the combination of load management and local storage totally nullifies the error in electricity forecasts.

The annual self-consumption factor without battery and with battery for all models can be observed in Table 5 . The differences between both forecast models and the reference ideal predictor model are small. More significant is the difference between using or not local storage: the use of local storage not only reduces the impact of forecast errors, it also improves the self-consumption by around $40 \%$ for all models.
Table 5

Annual self consumption factor.

\begin{tabular}{llll}
\hline \multirow{2}{*}{ Battery size (days of autonomy) } & \multicolumn{3}{l}{ Model } \\
\cline { 2 - 4 } & ARIMA & HIRLAM & REAL \\
\hline 0 & 0.485 & 0.490 & 0.519 \\
0.5 & 0.851 & 0.835 & 0.837 \\
\hline
\end{tabular}

Table 6 shows the excess electricity fed into the grid from the PV system in an annual basis for the three forecasts models and the two storage sizes. For comparison, the actual electricity produced by the PV system is also included in Table 6 . For a given storage size, the excess electricity for HIRLAM and ARIMA is very close to the ideal case. For a storage capacity of 0.5 days of autonomy the electricity fed into the grid during a year is $46 \%$ of actual generation; the differences between models are smaller than $50 \mathrm{kWh} /$ year. If no battery is used, the excess electricity raises to $71-72 \%$ (depending on model) of PV generation. The difference between ideal predictor and the other two models is smaller than $150 \mathrm{kWh} /$ year. The cumulative distribution functions (CDF) of daily excess electricity for the three models with a storage capacity of 0.5 days of autonomy are depicted in Fig. 6. The CDF of the daily electricity generated by the PV system is also included. The CDF for HIRLAM, ARIMA and the ideal predictor are closely matched. The uncertainty in forecasting is irrelevant in terms of excess electricity when ADSM and local storage are employed to increase self-consumption. Another important result in Fig. 6 is that the maximum daily electricity fed into the grid by the system would be $23 \mathrm{kWh}$ in comparison with $36 \mathrm{kWh}$ of maximum daily generation of the PV system. The reduction in the upstream flow of PV electricity in the distribution circuit has been reduced by $36 \%$, alleviating technical problems related to voltage rises and overloading the distribution line.

Finally, an economic analysis has been carried out to complete the findings of this study. The main assumption for this analysis is that all self-consumed electricity is valued at the domestic retail price of electricity. Due to the impossibility of consuming all the
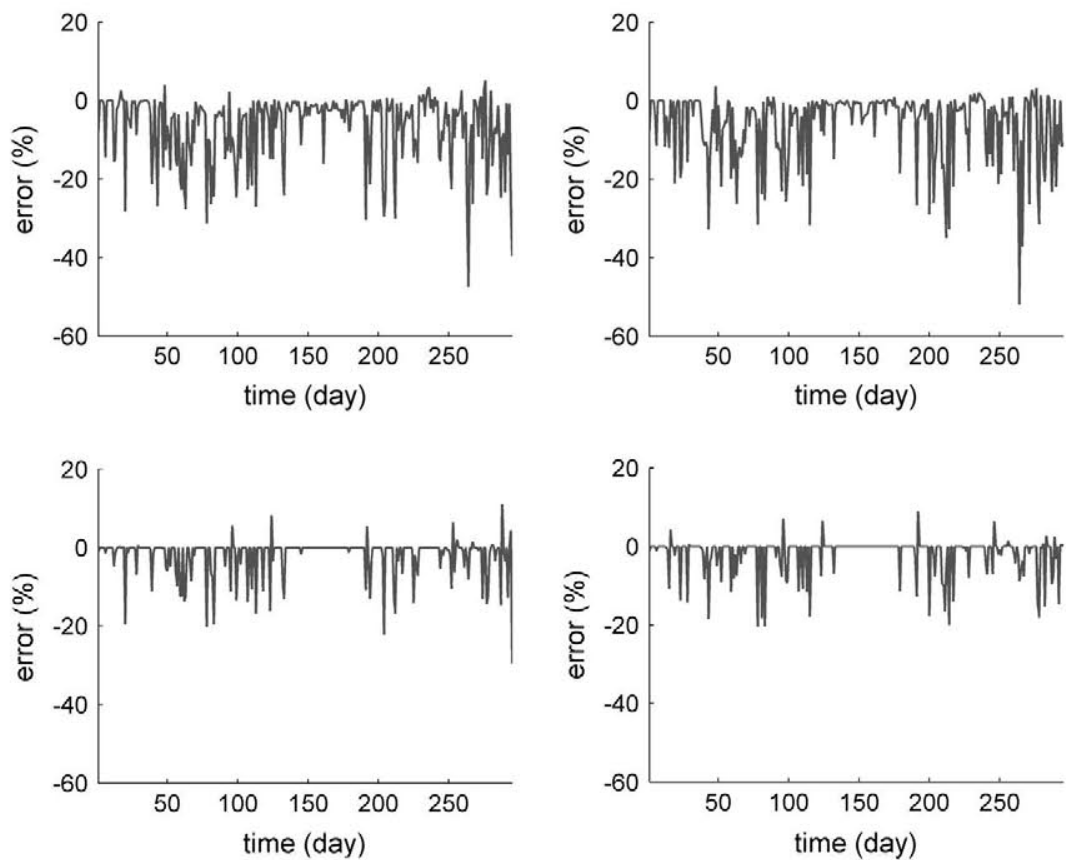

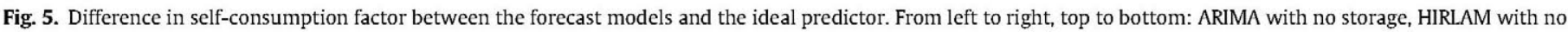
storage, ARIMA with an autonomy level of 0.5 days, HIRLAM with an autonomy level of 0.5 days. 
Table 6

Excess electricity fed into the grid.

\begin{tabular}{lll}
\hline Model & Battery size (days of autonomy) & Excess electricity $(\mathrm{kWh})$ \\
\hline HIRLAM & 0 & 5280.3 \\
HIRLAM & 0.5 & 3374.6 \\
ARIMA & 0 & 5298.8 \\
ARIMA & 0.5 & 3378.2 \\
Ideal & 0 & 5157.0 \\
Ideal & 0.5 & 3330.5 \\
PV & - & 7303.0 \\
\hline
\end{tabular}

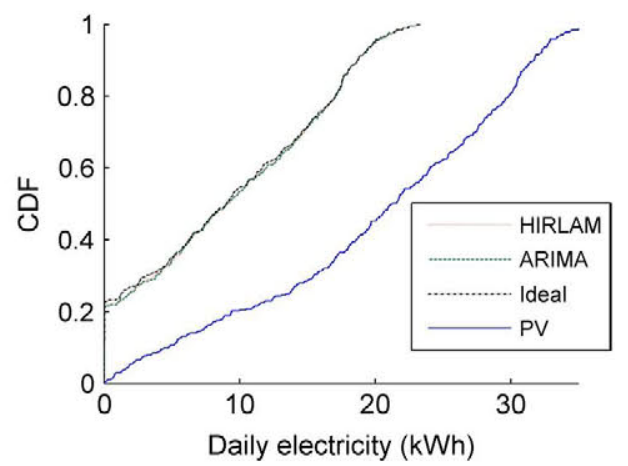

Fig. 6. Cumulative distribution functions of daily excess electricity for HIRLAM, ARIMA and ideal predictor. The storage capacity for all cases is 0.5 days of autonomy. The case of all generated electricity fed into the grid is also shown.

generated electricity, even with the use of local storage (self-consumption factor is never 1 as shown by table 5), two cases have been considered for the excess electricity fed into the grid: that it is either paid at the retail price (net-metering) or that it is paid at pool price. The retail price is $19 \mathrm{cE} / \mathrm{kWh}$ including taxes. This is the price of the last-resource tariff in Spain which is widely used in the residential sector and it does not depend on the hour of day. The pool price has been assumed to be $6 \mathrm{c} € / \mathrm{kWh}$, which is the average of market price in Spain during 2012. Both prices are supposed to increase by $2.5 \%$ every year. This increase is real in the sense that it excludes the effects of inflation.

Regarding system costs, it has been assumed that the only costs for the user are the installation of the PV system and the battery. Two battery sizes have been considered: no battery and a battery with 0.5 days of autonomy. Although remote-controlled appliances have been used in Magic Box, they are not mandatory to adopt ADSM strategies; the GEDELOS-PV system can provide the user the times at which the deferrable loads must run and they can be programmed manually (most appliances in the market today include this option). The GEDELOS-PV system, or any similar control software, is assumed to be distributed freely. This software can be run in a few seconds on any standard PC or even a smartphone, which are common in most households today, so it is not necessary to purchase additional equipment. The cost of the PV system is $2 € /$ $\mathrm{W}_{\mathrm{P}}$, which is consistent with market prices in Spain for PV systems of few kilowatts. The cost of the battery has been assumed to be $0.8 € / \mathrm{kWh}$. No battery systems are commercially available at Spain for domestic self-consumption so this price is the average price of the German market [46]. The life of the PV system has been fixed to 30 years. In consequence, 30 years is the period considered for the analysis. It has been assumed that the inverter is changed once during the lifetime of the system at the 16th year and the battery is replaced twice at 11 th and 21 st year. The prices of inverter and battery are reduced by $2 \%$ every year. The $25 \%$ of the original value of the battery is recovered through recycling. The cost of the inverter at year 0 is assumed to be $0.2 € / \mathrm{kW}_{\mathrm{P}}$ [47]. The size of the PV system is $6210 \mathrm{~W}_{\mathrm{P}}$, its generation is the actual measured generation which is reduced every year by $0.5 \%$ due to aging. No subsidy or feeding-in-tariff have been considered.

The economic viability of the system has been evaluated by comparing the income generated (consumption avoided from the grid at retail price plus electricity fed at either pool price or retail price) with earnings generated if the same amount of money spent in the system would have been invested at a real not-inflated interest rate of $3 \%$. Higher interest rates have not been considered because, given the small amount of money involved and the profile of the user, it is not likely that the user would have opted for a higher interest rate product with a higher financial risk. Also, it has been considered that the cost of the PV system is not loaned and, therefore, no financial costs are incurred. Fig. 7 shows the evolution of the incomes generated by the system and the alternative of investing the money at a fix interest rate. It must be noted that the results shown here depend strongly on the assumptions on which the analysis is based and the results can be altered on either way by different assumptions. The sudden steps in the later are caused by the cost of replacing inverter and battery. When local storage is not included in the system (upper figure), the most profitable option is net-metering which amounts a total of $58329 €$ at the end of the 30th year. The combination of retail and pool price and the investment at fix interest are very close: $30408 €$ and $30656 €$ respectively. If a local storage of 0.5 days of autonomy is used, the net metering option is still the most profitable with a total earning of $54544 €$. In this case, investing at an interest rate of $3 \%$ is the second best option: $48848 €$. The combination of retail price for self-consumed energy and pool price for excess energy is lower than the other two cases, generating $37866 €$ at the end of the period. This later case does not means that the system is unprofitable, indeed the profit provided by the system in real terms is higher than its cost at the 30th year.
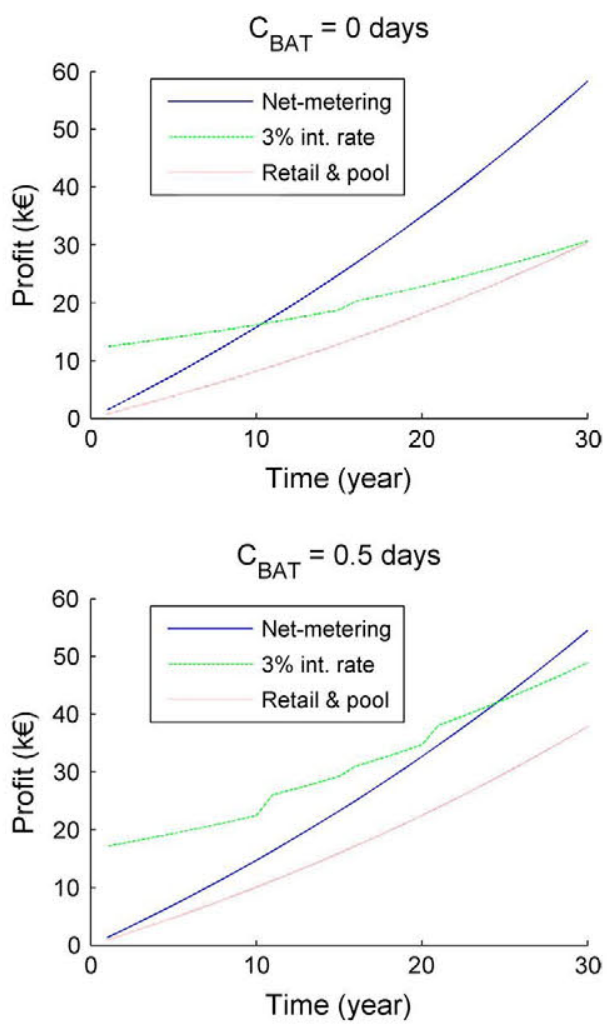

Fig. 7. Profit accumulated over 30 years for net-metering and mix of retail and poo prices compared to profit at an interest rate of $3 \%$. Upper figure correspond to a system with no storage and lower figure corresponds to a system with storage. 
The Levelized Cost of Electricity (LCOE) for both storage sizes have been also estimated. The LCOE allows to compare different technologies and represents the cost of the energy generated in real terms discounting the effects of inflation. LCOE is defined in Eq. (4).

$\operatorname{LCOE}=\frac{\sum_{i=0}^{N} C_{i} /(1+r)^{i}}{\sum_{i=1}^{N} q_{i} /(1+r)^{i}}$

where $N$ is the lifetime of the generating plant; $C_{i}$ is the cost at the year $i$ associated to the plant, including installation, operation, maintenance, fuels (if needed), etc.; $q_{i}$ is the electricity generated at the year $i$ and $r$ is the discount rate.

The values of generated electricity and costs are the same that were used in the analysis of economic viability. $N$ is also 30 years. The discount rate, which includes the effect of inflation, is $5 \%$. The resulting $\mathrm{LCOE}$ for the system is $11 \mathrm{c} \in / \mathrm{kWh}$ if no battery is used and $14 \mathrm{c} € / \mathrm{kWh}$ when local storage is included in the system. In both cases, the system can compete in price with retail electricity but it is still more expensive than the pool price. However, in this calculation the effect of time and place of generation, identified by Borenstein, have not been taken into account $[48,49]$. These effects would have lowered the LCOE because a distributed PV system can generate electricity at congested nodes of the electric grid and this generation happens during peak demand, when the market value of electricity is higher. Furthermore, these effects are enhanced by the use of ADSM and local storage.

\section{Conclusions}

The variability of the solar resource makes electricity generation by PV systems difficult to control, which limits its integration in the grid. Additional measures to mitigate the impact of the high level of uncertainty in forecasting generation are needed. The GEDELOS-PV system has been presented in this paper, which aims at the integration of distributed PV generation in the residential sector together with ADSM and local storage.

The use of ADSM reduces the impact of uncertainty in PV electricity forecast, and the addition of a small amount of local storage further reduces the effect of forecast uncertainty, which is the major drawback for large-scale deployment of renewable energy sources. Mean daily forecast errors around $40 \%$ would happen when the PV system presented in this paper operates as a pure generator feeding all the electricity generated into the grid. On the contrary, mean daily forecast errors would be reduced to $2 \%$ when the PV system is coupled to a residential load and the energy exchanged with the electricity grid, measured through the selfconsumption factor, is forecasted.

Furthermore, a non-centralized forecast model allows for a complete distributed system. The ARIMA model is a non-centralized forecast model relatively easy to implement due to its low computational effort. This forecast model, in combination with ADSM techniques, allows users to increase self-consumed PV electricity without dependence on external services for the provision of generation forecasts. Therefore, the development of distributed PV generation on a scenario of smart grids, where users take an active role optimizing their own electricity consumption and generation, is facilitated.

The LCOE of the system, 11-14 c $€ / \mathrm{kWh}$, is lower than the retail price of electricity and, therefore, its implantation in the residential sector is economically viable. If net-metering is adopted, the profitability of the system is high (better than 3\%). If net-metering is not adopted and the excess electricity is sold to the grid at pool price, the profitability is still attractive for the case of a system without battery. The profitability is reduced if local storage is included due to the increase of cost caused by the battery.

\section{Acknowledgements}

M. Castillo-Cagigal is sponsored by the Spanish Ministry of Education with a Ph.D grant (FPU-2010). E. Matallanas is sponsored by the Spanish Ministry of Education with a Ph.D grant (FPU-2011). This work has been partly funded by the Spanish Education and Science Ministry under the ENE2007-66135 grant, the Spanish Science and Innovation Ministry under the IPT-2011-1468-920000 grant and the Spanish Economy and Competitiveness Ministry under the IPT-2012-1072-120000 grant. The authors want to thank the Escuela Técnica Superior de Ingenieros de Telecomunicación of the UPM for its support in the construction and maintenance of Magic Box.

\section{Appendix A. HIRLAM model}

HIRLAM stands for HIgh Resolution Limited Area Model and is a numerical short-range weather forecasting system developed by a cooperative scientific program between nine European meteorological institutes from the following countries: Denmark, Estonia, Finland, Iceland, Ireland, Netherlands, Norway, Spain and Sweden. The use of a numeric weather prediction model is the more straightforward way to obtain meteorological forecasts since they are provided externally from meteorological agencies or private companies.

HIRLAM forecasts directly a number of variables, i.e. prognostic variables, which are ambient temperature, horizontal and vertical wind components, humidity, cloud water, pressure and geopotential height. The initial condition for the model is derived from direct observations and extrapolation of these variables. The rest of variables, like irradiation, are derived from these prognostic variables. Since HIRLAM is a regional model, it needs a global model to act as host model and to provide lateral boundary conditions. The global ECMWF model is used as host model for HIRLAM. A general description of the HIRLAM system as well as specific information about its radiation scheme can be found in [50,51]. In the system presented in this paper, irradiance and ambient temperature forecasts based on HIRLAM were provided by the Spanish Meteorological Agency $\left(\right.$ AEMET $\left.^{1}\right)$.

\section{Appendix B. ARIMA model}

A time series is a sequence of values, measured successively at uniform intervals. The values are indexed by their position within the series - although called time series, this index must not be necessarily related to time measurements. Time series analysis can be used to understand the behaviour of some observed data or to forecast future values of this data. In this sense, autoregressive integrated moving average models (ARIMA) are a common tool used in time series analysis for forecasting future values of the series [52].

ARIMA represents the influence of past values of the time series, the so called "history" of the series, in future values by a combination of autoregressive (AR) and moving average (MA) models. The ' $\mathrm{I}$ ' in ARIMA stands for integrated, meaning that a time series may need an initial differencing step to remove non-stationary behaviour. In an autoregressive process, the value of an element of the time series associated to the process only depends on previous values. In a moving average process the current state is combination of random factors, independent to each other, which are

\footnotetext{
www.aemet.es
} 
modelled as white noise. The expression of a regular ARIMA process is given in Eq. (5):

$\nabla^{d} z_{t}-\sum_{i=1}^{p} \varphi_{i} \nabla^{d} z_{t-i}=a_{t}-\sum_{i=1}^{q} \theta_{i} a_{t-i}$

where $z_{t}$ is the time series, $a_{t}$ are random variables added to the model to prevent it from being deterministic, $\nabla$ is the first backward difference operator $\left(\nabla z_{\mathrm{t}}=\mathrm{z}_{\mathrm{t}}-\mathrm{z}_{\mathrm{t}-1}\right), d$ is the number of differences applied to the time series, $\varphi_{i}$ are the coefficients of the autoregressive part, $\theta_{i}$ are the coefficients of the moving averages part, $p$ and $q$ are the orders of the regular autoregressive and moving averages processes respectively. The above ARIMA model is denoted as $\operatorname{ARIMA}(p, d, q)$.

Besides the regular behaviour that Eq. (5) describes, some series exhibit seasonal behaviour, repeating the same pattern every fix number of terms. The behaviour of the time series can then be split into two components: a regular trend and a seasonal trend. The general expression of an ARIMA process is then:

$$
\begin{gathered}
\nabla^{d} z_{t}-\sum_{i=1}^{p} \varphi_{i} \nabla^{d} z_{t-i} \times \sum_{i=1}^{p} \Phi_{i} \nabla^{D} z_{t-L \times i} \\
=a_{t}-\sum_{i=1}^{q} \theta_{i} a_{t-i} \times \sum_{i=1}^{Q} \mathrm{O}_{i} a_{t-L \times i}
\end{gathered}
$$

where $L$ is the seasonality of the series, $D$ is the number of seasonal differences applied, $\Phi_{i}$ are the coefficients of the seasonal autoregressive part, $\Theta i$ are the coefficients of the seasonal moving averages part and $P$ and $Q$ are the orders of the seasonal processes. The structure of the above ARIMA model is ARIMA $(p, d, q) \times(P, D, Q)_{L}$.

The orders of the processes in an ARIMA model $(p, q, P, Q)$, the seasonality $(L)$ and the differences needed $(d, D)$ are identified through the autocorrelation function (ACF) and partial autocorrelation function (PACF) of the time series $z_{t}$. The ACF provides information of the moving average part of the model, if any, and the PACF provides information of the autoregressive part.

The forecasts of meteorological variables with ARIMA in this study have been performed following the Box-Jenkins methodology. This methodology is summarized below, although detailed information can be found in [52].

(1) Non-stationarity removal. ARIMA modeling must be applied only to time series that are stationary. A time series is non-stationary when its mean and variance are not constant along the series. Mean is stationarized by differencing the time series. Variance is stationarized by applying a transform to the series. In this study the irradiance series was stationarized by replacing it with clearness index values. The use of the clearness index was chosen instead of applying the log transform, which is commonly used for stationarizing an ARIMA process, because it as more natural transform for irradiation.

(2) Model identification. On this study, the ACF and PACF from the initial 65 days of the original set of data, whose full length is 365 days, have been estimated. From these correlation functions the structures of the ARIMA models explaining the irradiation and ambient temperature series have been determined.

(3) Coefficients estimation. After determining the structures of the models, the coefficients associated to the autoregressive and moving average processes $\left(\varphi_{i}, \Phi_{i}, \theta_{i}, \Theta_{i}\right)$ have been fit with the least squares method. The set of data of the previous step, 65 initial days, has been used to fit the models.

(4) Forecasts estimation. Forecasts for the remaining 300 days of the original set of data were estimated using the ARIMA models built in the previous steps. For every day, the actual measurements from the 65 previous days are extracted from the original set of data. These values, 1560 hourly values in total, initialize the ARIMA model in order to forecast the 24 hourly values of the next day through the use of Eq. (6).

\section{References}

[1] Internacional Energy Agency. Trends in Photovoltaic Applications in selected IEA countries between 1992 and 2010; 2011. <http://www.iea-pvps.org/ index.php?id=92>, [accessed 11.09.12].

[2] IPCC. IPCC Special Report on Renewable Energy Sources and Climate Change Mitigation. In: Edenhofer O, Pichs-Madruga R, Sokona Y, Seyboth K, Matschoss P, Kadner $S$ et al. editors, Prepared by Working Group III of the Intergovernmental Panel on Climate Change. Cambridge University Press: Cambridge, United Kingdom and New York, NY, USA; 2011. p. 1075.

[3] Kjärstad J, Jonson F. Resources and future supply of oil. Energy Policy 2009;37:441-64.

[4] Red Eléctrica Española (REE). El informe eléctrico español 2010; 2011.

[5] Bundesministerium für Umwelt, Naturschutz und Reaktorsicherheit (BMU) Development of renewable energy sources in Germany in 2010; 2011. <http:// www.bmu.de/files/english/pdf/application/pdf/ ee_in_deutschland_graf_tab_en.pdf $>$, [accessed 05.09.12]

[6] Connolly D, Lund H, Mathiesen BV, Leahy M. A review of computer tools for analysing the integration of renewable energy into various energy systems. Appl Energy 2010;87:1059-82.

[7] Mathiesen BV, Lund H, Karlsson K. 100\% Renewable energy systems, climate mitigation and economic growth. Appl Energy 2011;88:488-501.

[8] Krajacic G, Duic N. Carvalho MdG. How to achieve a 100\% RES electricity supply for Portugal? Appl Energy 2011;88:508-17.

[9] Thiam DR, Benders RM], Moll HC. Modelling the transition towards a sustainable energy production in developing nations. Appl Energy 2012;94:98-108.

[10] Lorenz E, Scheidsteger T, Hurka J, Heinemann D, Kurz C. Regional PV power prediction for improved grid integration. Prog Photovoltaics Res Appl 2011;19:757-71.

[11] Bacher P, Madsen H, Nielsen HA. Online short-term solar power forecasting. Sol Energy 2009;83:1772-83.

[12] De Giorgi MG, Ficarella A, Tarantino M. Assessment of the benefits of numerical weather predictions in wind power forecasting based on statistical methods. Energy 2011;36:3968-78.

[13] Foley AM, Leahy PG, Marvuglia A, McKeogh EJ. Current methods and advances in forecasting of wind generation. Renew Energy 2012;37:1-8.

[14] Koeppel G, Korpas M. Improving the network infeed accuracy of nondispatchable generators with energy storage devices. Electr Power Syst Res 2008;78:2024-36.

[15] Di Giorgio A, Pimpinella L. An event driver smart home controller enabling consumer economic saving and automated Demand Side Management. App Energy 2012;96:92-103.

[16] Dallinger D, Gerda S, Wietschel M. Integration for intermittent renewable power supply using grid-connected vehicles - A 2030 case study for California and Germany. Appl Energy 2013;104:666-82.

[17] Arteconi A, Hewitt NJ, Polonara F. State of the art of thermal storage for demand-side management. Appl Energy 2012;93:371-89.

[18] Schroeder A. Modeling storage and demand management in power distribution grids. Appl Energy 2011;88:4700-12.

[19] Stadler M, Kloess M, Groissböck M, Cardoso G, Sharma R, Bozchalui MC, et al. Electric storage in California's commercial buildings. Appl Energy 2013; 104:711-22

[20] Wissner M. The smart grid - a saucerful of secrets? Appl Energy 2011;88:2509-18.

[21] Zhang Q, Mclellan BC, Tezuka T, Ishihara KN. An integrated model for longterm power generation planning toward future smart electricity systems. App Energy. <http://dx.doi.org/10.1016/j.apenergy.2013.03.073>.

[22] Strbac G. Demand side management: benefits and challenges. Energy Policy 2008;36:4419-26.

[23] Ministero dello Svilupo Economico (Italy). Decreto interministeriale 5 maggio 2011 - Produzione energia elettrica da impianti solari fotovoltaici, tecnologie innovative conversione fotovoltaica; 2011.

[24] Denholm P, Margolis RM. Evaluating the limits of solar photovoltaics (PV) in traditional electric power systems. Energy Policy 2007;35:2852-61.

[25] Denholm P, Margolis RM. Evaluating the limits of solar photovoltaics (PV) in electric power systems utilizing energy storage and other enabling technologies. Energy Policy 2007;35:4424-33.

[26] Lund P. Large-scale urban renewable electricity schemes. Energy Convers Manage 2012;63:162-72.

[27] Caamaño-Martín E, Egido MA. Spanish participation in the "Solar Decathon 2005" competition: new proposals for zero-energy houses. Proc 20th EUPVSEC, Barcelona (Spain); June 2005. p. 2587-90.

[28] Calvo-Fernández M, Vega JE, Egido MA, Caamaño-Martín E. Spanish participation in the "Solar Decathon 2005" competition: design and simulation of the Photovoltaic system. Proc 20th EUPVSEC, Barcelona (Spain); June 2005. p. 1958-63. 
[29] International Electrotechnical Commission. Photovoltaic devices. Part 2: requirements for reference solar cells. 60904(2); 1989.

[30] International Electrotechnical Commission. Electricity metering equipment (a.c.). Particular requirements. Part 21: Static meters for active energy. 62053(21); 2003.

[31] Tanenbaum AS, Oteen MV. Distributed systems: principles and paradigms. Upper Saddle River (NI, USA): Prentice-Hall; 2006.

[32] Castillo-Cagigal M, Gutiérrez A, Monasterio-Huelín F, Caamaño-Martín E, Masa D, Jiménez-Leube J, et al. A semi-distributed electric Demand-Side Management System with PV generation for self-consumption enhancement. Energy Convers Manage 2011;52:2659-66.

[33] Matallanas E, Castillo-Cagigal M, Gutiérrez A, Monasterio-Huelin F, Caamaño E Masa D, et al. Neural network controller for Active Demand-Side Management with PV energy in the residential sector. Appl Energy 2012;91:90-7.

[34] Castillo-Cagigal M, Caamaño-Martín E, Matallanas E, Masa-Bote D, Gutiérrez A Monasterio-Huelín F, et al. PV self-consumption optimization with storage and active DSM for the residential sector. Sol Energy 2011;85:2338-48.

[35] Osterwald CR. Translation of device performance measurements to reference conditions. Sol Cells 1986;18:269-79.

[36] International Electrotechnical Commision. Crystalline silicon terrestrial photovoltaic (PV) modules. Design qualification and type approval. 61215 2005.

[37] Masa D, Caamaño-Martín E, Calvo M. Estimation of Shadow Effects Using Digital Tools. Proc 22nd EUPVSEC, Milan (Italy); September 2007. p. 2983-7.

[38] Martin N, Ruiz JM. Calculation of the PV modules angular losses under field conditions by means of an analytical model. Sol Energy Mater Sol Cells 2001;70:25-38.

[39] Schmidt H, Sauer DU. Praxisgerechte und praezise Modellierung von Wechselrichter-Wirkungsgraden. IX International Solar, Forum, Stuttgart; 1997.
[40] REE, 1998. Proyecto INDEL, Atlas de la Demanda Electrica Espanola. Project Final Report, Madrid (Spain).

[41] Mellit A, Pavan AM. A 24-h forecast of solar irradiance using artificial neural network: application for performance prediction of a grid-connected PV plant at Trieste Italy. Sol Energy 2010;84:807-21.

[42] Paoli C, Voyant C, Muselli M, Nivet ML. Forecasting of preprocessed daily solar radiation time series using neural networks. Sol Energy 2010;84:2146-60.

[43] Marquez R, Coimbra CFM. Forecasting of global and direct solar irradiance using stochastic learning methods, ground experiments and the NWS database. Sol Energy 2011;85:746-56.

[44] Reikard G. Predicting solar radiation at high resolutions: a comparison of time series forecasts. Sol Energy 2009;83:342-9.

[45] de Almeida A, Fonseca P, Schlomann B, Feilberg N. Characterization of the household consumption in the EU, potential energy savings and specific policy recommendations. Energy Build 2011;43:1884-94.

[46] Krause MB. Expanding the range. Photon Ing 2012;12:118-23.

[47] Naujoks I, Krause MB. The little inverter that could. Photon Int 2013;3:44-6.

[48] Borenstein S. The Market Value and Cost of Solar Photovoltaic Electricity Production. Center for the Study of Energy Markets; 2008. <http:// www.ucei.berkeley.edu/PDF/csemwp176.pdf>, [accessed 02.07.13].

[49] Borenstein S. The private and public economics of renewable electricity generation. J Econ Perspect 2012;26(1):67-92.

[50] Undén P, Rontu L, Järvinen H, Lynch P, Calvo J, Cats G et al. HIRLAM-5 Scientific Documentation. December; 2002. <http://hirlam.org>, [accessed 15.01.13].

[51] Savijärvi $H$. Fast radiation parameterization schemes for mesoscale and shortrange forecast models. J Appl Meteorology 1990;29:437-47.

[52] Peña D, Tiao GC, Tsay RS. A course in time series analysis. New York (USA): John Wiley; 2001. 